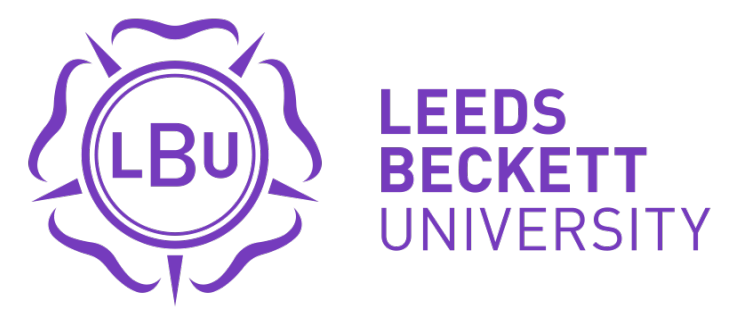

Citation:

Zhang, J and Wu, J and Simpson, J and Arthur, C (2019) Membership of Chinese Farmer Specialized Cooperatives and Direct Subsidies for Farmer Households: A Multi-Province Data Study. The Chinese Economy: translation and studies, 52 (5). pp. 400-421. ISSN 0009-4552 DOI: https://doi.org/10.1080/10971475.2019.1617928

Link to Leeds Beckett Repository record:

https://eprints.leedsbeckett.ac.uk/id/eprint/5855/

Document Version:

Article (Accepted Version)

Creative Commons: Attribution-Noncommercial-No Derivative Works 4.0

The aim of the Leeds Beckett Repository is to provide open access to our research, as required by funder policies and permitted by publishers and copyright law.

The Leeds Beckett repository holds a wide range of publications, each of which has been checked for copyright and the relevant embargo period has been applied by the Research Services team.

We operate on a standard take-down policy. If you are the author or publisher of an output and you would like it removed from the repository, please contact us and we will investigate on a case-by-case basis.

Each thesis in the repository has been cleared where necessary by the author for third party copyright. If you would like a thesis to be removed from the repository or believe there is an issue with copyright, please contact us on openaccess@leedsbeckett.ac.uk and we will investigate on a case-by-case basis. 


\title{
Membership of Chinese Farmer Specialized Cooperatives and Direct Subsidies for Farmer Households: A Multi-Province Data Study
}

\author{
JINHUA ZHANG, JUNJIE WU1, JUSTINE SIMPSON, CLEMENT LAMBOI ARTHUR
}

\begin{abstract}
The introduction of direct subsidies to farming households and the development of farmer cooperatives has provided two important approaches to China's twenty-first century food policy challenges. However, research undertaken largely separates and focuses on subsidies or cooperatives. This neglects their interaction and complementarities. This paper seeks to rectify this omission using a survey from 35 farmer specialized cooperatives (FSCs) and 561 farming households in 16 provinces, based on a two-stage treatment effect model. The findings suggest FSCs have become important organizations that improve farmers' net income. Moreover, usage of agricultural machinery and direct subsidies also result in higher net income, though they have little impact on farmers' machinery investment. The results provide an evidence source that contributes to debate concerning government subsidy policy. Policy may act more like an income transfer program, since it has little impact on farmers' investment in agriculture. The study also highlights that there are complementary effects between FSCs and direct subsidies, and that China's cooperative policy integrated with direct subsidies could
\end{abstract} be progressive.

Keywords: Farmer Specialised Cooperatives (FSCs), agricultural subsidies, farmers' net income, agricultural development, China.

JEL: O13, P21, Q01, Q18

Food security is a key issue for any nation. Agriculture therefore is a core policy issue for any government and this extends to the role of subsidies to farming households and policies supportive of cooperatives (Yi et al. 2015; Zheng et al. 2012; OECD 2009). Contemporary China confronts a particular tension in terms of food security because rapid urbanization has caused a significant decrease in the farming population and has threatened sustainable agricultural development (Carter et al. 2012; Tian and Zhou 2011). Geographically, China has less than 0.4 hectares per capita of agricultural land, of which a minority is arable (less than 0.09 hectares per capita). However, China is home to around 1.4 billion people, almost

\footnotetext{
${ }^{1}$ Jinhua Zhang is lecturer at College of Economics and Management, Zhejiang University of Technology, Hangzhou, China; email: celliazjh@zjut.edu.cn. Junjie Wu is Reader and the corresponding author at Leeds Business School, Leeds Beckett University, UK; email: J.Wu@leedsbeckett.ac.uk. Justine Simpson is principal lecturer at Leeds Business School, Leeds Beckett University, UK; email: J.Simpson @ leedsbeckett.ac.uk. Clement Lamboi Arthur is lecturer at School of Business, University of Cape Coast, Ghana; email: carthur@ucc.edu.gh. The authors are grateful to Professor Jamie Morgan of Leeds Beckett University for his inspiration and support, and to Professor Hung-gay Fung, the editor-in-chief of Chinese Economy for his constructive comments and useful guidance. This research was financially supported by Zhejiang Philosophy and Social Science Project under Grant No.17NDJC228YB, Natural Science Foundation of China under Grant No.71603238, Humanities and Social Sciences projects of the Ministry of Education under Grant No.18YJA790075, and Zhejiang Provincial Natural Science Foundation of China under Grant No.LQ19G010002.
} 
$20 \%$ of the world population. The Chinese state is thus highly sensitized to the need to support the agricultural sector.

Since 2003/2004, direct subsidies to farming households have become a key component in China's national agricultural development policy. A subsidy may contribute to income or productive capacity or both, and this has in turn created scope for research. Huang et al.'s (2013) fieldwork clearly establishes that contemporary subsidies to farming households in China have been significant, proportional to agricultural GDP, and, as subsidies flow to rural households as recipients, one can reasonably infer generalized benefits in terms of income effects. Huang et al.'s study also tracks increasing total value of output for grains (rice, wheat and corn) and soybeans, from which one can infer some degree of positive association between output (at least by value) and subsidies. However, as Huang et al. (2011) also make clear, institutional frictions have reduced the effectiveness of subsidies. For example, the dominant grains subsidy has been distributed on the basis of longstanding contracted land areas, and so has flowed to named contractees, rather than the farmer currently planting on this land (Kirwan 2008; Huang et al. 2011). As such, the subsidy has created more of a generalized income effect than a direct output effect (its impact seems to be distorted or dissipated). The issue remains an important one in terms of evolving contexts.

Contemporary farmer specialized cooperatives (FSCs) began to emerge in the 1980s as a solution to problems confronted by the introduction of markets for farm produce, initially pioneered by an echelon of better connected and relatively wealthy farmers (Liang and Hendrikse 2013). These cooperatives were voluntary mutual aid organizations and so can be clearly differentiated from former forced collectivization, characteristic of the 1950s-1960s (see Zheng et al. 2012). However, the new cooperatives were in turn hampered by the absence of a legal framework that could encourage dissemination of these organizations through the clarification of rights and obligations, and by improving awareness of the potential of this new organizational form (Chan and Ip 2014a, 2014b). Despite the absence of a framework, local government began to promote farmer cooperatives in the 1990s and this culminated in 1998 in a Directive from the State Council providing national recognition and support for them. This was followed in 2002 by a Ministry of Agriculture pilot scheme, which focused on 100 FSCs in order to develop a legal framework. As such, the state began to take a formal interest in farmer cooperatives, at around the same time as the policy of direct subsidies to farming households was being developed. In 2004, Zhejiang Province passed the first provincial law to regulate FSCs and this, in conjunction with the pilot scheme, was then used as the basis for the national Farmers' Specialised Cooperative Law, which came into effect in July 2007. The implementation of the new law clearly provided a significant impetus to the growth of cooperatives. 
The direct subsidy policy and the Farmers' Specialised Cooperative Law have long since been implemented (as of 2018, 14 and 11 years respectively). However little research has been focused on the possible scope for complementarities between these two policies. Huang et al.'s (2013) work, was focused overwhelmingly on subsidies and they acknowledged that one limitation of their research was that it put aside other important issues such as membership of a farmer specialised cooperative (FSC). Zheng et al.'s (2012) prior work explores factors affecting participation in FSCs, but focuses only on this. Moreover, their data derives only from Jilin Province.

The purpose of our paper is to assess the role of cooperatives as a complement to work undertaken on direct subsidies (i.e. the complementarity between these two polices). We do so using multi-province data. To achieve this aim, we collected 561 farmer household surveys across 16 provinces, covering 35 FSCs and using a group of non-FSC members as a control group. The survey data focuses on three issues: (1) factors affecting farmer's participation in FSCs; (2) the net income effects of FSCs membership and direct subsidies for farmers; (3) the impact of membership and direct subsidies on investment in agricultural inputs and use of machinery. Since much of the research on FSCs tends to be more localized, our construction of the data covering a range of provinces allows us to extend the prior focus and extent of the aforementioned research.

Our findings have important policy implications concerning the integration and the development of cooperatives and agricultural direct subsidies. Overall, they provide further empirical support for the argument that effective integration of cooperatives with direct subsidies is likely to be a positive policy combination, especially if also combined with structural reform in the agricultural sector. The rest of the paper is organized as follows: Section 2 provides a brief overview of the emergence of FSCs and new subsidies policies; Section 3 introduces the data and model, Section 4 sets out the empirical results and analysis, and in Section 5, we conclude with a brief discussion of the policy implications.

\section{Context: The emergence of FSCs and new subsidies policies}

Agriculture is a critical sector for China (Cai and Du 2006). China has 7\% of the world's cultivated land feeding nearly a quarter of the world's population. Agricultural development is thus a priority for the Chinese government historically and contemporarily. The epithet "Food is the first thing for people" ( $m i n$ yi shi wei tian) captures an enduring concern in Chinese civilization. Agricultural taxes and subsidies, have been frequently used by China's governments over a period of 2500 years. However, government rarely intervened to encourage 
the formation of farmer organizations prior to the Chinese Communist Party $(\mathrm{CCP})$ coming to power in 1949. A fragmented small farming economy was previously characteristic of Chinese agriculture. Since 1949, farmer organization and agricultural subsidy policies have been closely associated and have been key policies, even though dominant political concerns have been focused elsewhere.

To expedite rapid industrialisation, partly emulating the USSR (Union of Soviet Socialist Republics,) the CCP initiated a heavy industry-oriented development strategy from 1950, creating state-owned enterprises (SOEs). This resulted in a rapid expansion of the urban population and great demand for agricultural output. Grain self-sufficiency and statemonopolized grain procurement became core concerns. In addition, to support industrial development, the Chinese government collected agricultural taxes from individual farmers, which accounted for around $40 \%$ of total national taxation. However, support for agriculture in the form of machinery and subsidies was limited (Chen and Zhu 2012). The development of the industrial infrastructure at that time was at the expense of agricultural development and farmers' interests.

Beginning in the 1950s, in accordance with socialist ideological tenets, the CCP began to introduce collective farming. Farmers were initially persuaded to voluntarily join small farming teams. Policy, however, quickly became more pressured and then coercive. The late 1950's witnessed a rapid switch to 'People's Communes', each containing about 5,000 households, 10,000 labourers and 10,000 acres of cultivated land (Lin 1997). As has been well documented 'People's Communes' were a political and practical disaster. Farmers suffered within large bureaucratic organizations that espoused equal distribution policies but generated a variety of unintended consequences and oppressions. As a result, per capita grain output was consistently low. Problems were compounded by the Great Leap Forward in which approximately 30 million people died from starvation and malnutrition between 1959 and 1961 (Lin 1990, 1993). Though People's Communes were not formally abolished at this time, farmer organizations subsequently tacitly devolved to smaller unit sizes called 'Production Teams', which consisted of about 20-30 neighbouring households (Lin 1997).

Then in 1978, the CCP, following a spontaneous set of events in Anhui province, began to introduce some market based agricultural reforms, as well as broader economic reforms (the socialist market economy). In the agricultural sector, an incremental and experimental approach was implemented. To secure a substantial increase in agricultural output, a shift from the collective farming system to a household based farming system began in 1979 (completed 1984) (Lin 1997). This was named the 'Household Responsibility System'. The policy resulted in a sharp increase in grain output. However, agricultural reform within the command economy 
proceeded more slowly, but gradually extended from: (1) a gradual increase in grain procurement prices; (2) reductions in basic quota compulsory procurement, balanced by an above quota premium price; (3) a switch from mandatory quota procurement to contract procurement. Still, the grain procurement system was retained until the late 1980s, by which time the marketized system was more diverse and capacity had improved. In the 1990s, the government carried out further reforms, including protecting grain prices via subsidies. For example, price subsidies for grain, cotton and vegetable oil significantly increased from 26.76 billion yuan (RMB) in 1990 to 75.87 billion yuan (RMB) in 2000 (Chen and Zhu 2012). The agricultural machinery purchase subsidy was also added (He et al. 2010). Subsequent grain output growth was generally greater than population growth. However, more rapid economic reform outside the agricultural sector ultimately drove the government to adopt new legislation and deeper reforms in agricultural policy from the late 1990s.

After two decades of economic growth, the share of agriculture in GDP dramatically reduced from $35 \%$ in 1970 down to $15 \%$ in 2004 . However, thought this is typical of transitional development states it also created real disruptions. In the $2000 \mathrm{~s}$, the attractiveness of industrial and service based urban employment led to a rural outward migration problem and reflected an increasing rural-urban income gap. ${ }^{2}$ The total agricultural population fell from $82 \%$ in 1978 to $50 \%$ in the late 2000s (NBSC 2004-2009; cited in Deng et al. 2010). This migration cumulatively (and despite that much of the migration was ostensibly temporary and seasonal) resulted in an aging and female dominated rural population, characterised by lower skills and levels of education (in turn creating problems of both numbers and current capabilities for the implementation of farming reforms; modern management and technology use, supply chain awareness etc). The Chinese state came to recognize these as a source of crisis expressed through the 'three agricultural issues': farmers (nong min), countryside (nong cun) and agriculture (nong ye). Solving problems for each was recognized as necessary to achieve long term grain security and agricultural sustainability.

FSCs developed in this context (Zhao and Yuan 2014). FSCs built on skills and practices provided by a small proportion of middle class farmers, who had acquired substantial assets and social capital from the economic reforms, many of whom had exploited networks of connections to benefit from the reform process (via work at local government agricultural departments and positioning in new supply chains etc) (Zhao 2006; Liang and Hendrikse 2013). Beginning in the 1980s, these farmers organized cooperative-like activities to connect buyers and sellers. FSCs capitalised on the experience of these farmers and many of them became core members of the new FSCs in the 1990s (Liang and Hendrikse 2013). Importantly, unlike

\footnotetext{
${ }^{2}$ Rural migrant numbers reached 225.42 million in 2008 (NBSC 2009; cited in Gui et al. 2012), of which most are educated young people who were attracted by higher income, living styles and life prospects in urban cities.
} 
collectivist movements in the past, the new FSCs were driven by entrepreneurial farmers able to connect to both business and government (Xu et al. 2013).

FSCs brought together scattered small-scale farmer households, allowing economies of scale to be achieved, and increasing bargaining power with buyers, whilst reducing transaction costs (Taubmann et al. 2003; Zheng et al. 2011). Realising the potential, the government began to adopt supportive strategies and policies. As briefly noted in the introduction, in 1998, a Directive was issued by the State Council to declare government support for FSCs as a voluntary initiative. In 2002 the Ministry of Agriculture launched a 100 FSC pilot scheme across China to obtain experience to help prepare for legislation. In November 2004, Zhejiang Province passed the first provincial law to regulate the operation of FSCs. Using the local law as a reference, the $10^{\text {th }}$ National People's Congress issued the national 'Farmers' Specialised Cooperative Law' in October 2006, which came into effect on $1^{\text {st }}$ July 2007. Later the national Agricultural Law was amended to incorporate this new legislation. With legal protection and active government sponsorship, the numbers of FSCs grew rapidly. For example, the number registered with local government agriculture offices increased from 100,000 in 2008 (Yan and Chen 2013) to $15,310,000$ in $2015 .^{3}$ The latter figure constitutes $42 \%$ of farmers in China.

The shift to support for FSCs was accompanied by changes in the policy context for, and dependence on, agricultural taxes (Wang and Cai 2004). Agricultural tax revenue was no longer significant, falling from 11\% in 1970 to 3.7\% in 2004 (NBSC 2005; cited in Meng 2012). Joining the World Trade Organization (WTO) in 2001 required China to gradually comply with international rules and practices. Moreover, industrial and service led economic growth provided a platform for the Chinese government to invest more in agriculture and rethink its approach to subsidies.

In 2004 China began to phase out agricultural taxes and this was completed by 2006. Meanwhile, agricultural subsidy policy was reformed (Gale 2009; Zheng et al. 2013.). Reform included three main features: (1) a significant increase in the total value of subsidies; (2) a switch from indirect subsidies via procurement prices to a direct cash transfer into individual farmer's dedicated bank accounts; (3) the introduction of new subsidy categories and eligibilities. ${ }^{4}$ However, since 2016 there has been some reconsolidation of subsidy categories to ensure a more coherent system. ${ }^{5}$ Total agricultural subsidies steadily increased from 14.5

\footnotetext{
3 http://news.xinhuanet.com/politics/2016-03/21/c_128819262.htm

4 The four main general categories introduced (with subcategories in each) have been: 'grain subsidy' (liangshi butie), 'comprehensive (aggregated) input subsidy' (nongzi zonghe butie), 'quality seed subsidy' (liangzhong butie) and 'agricultural machinery subsidy' (nongjiju butie).

5 'grain subsidy', 'comprehensive (aggregated) input subsidy', and 'quality seed subsidy' have since been combined and are now termed the 'agriculture support and protection subsidy'.
} 
billion RMB yuan in 2004 to 123.1 billion yuan in 2009 (Meng 2012). ${ }^{6}$ This increased again to 140.5 billion in $2016 .^{7}$

The brief contextualizing overview provided here indicates that agriculture has become a less significant part of China's overall economy in GDP and developmental terms, but that the government has increasingly recognized the need to support and develop its agricultural sector. There are many points one might make here regarding social cohesion and stability, sustainability, and future food security. However, one important empirical issue is the degree to which cooperatives policy and subsidies policy have been successful, and the degree to which these two can or could complement each other, since given the actual profile of China's farming sector effective policy along these axes creates scope to pursue goals such as those just stated. Our study contributes along these lines.

Bearing in mind that there have been few studies of cooperatives and subsidies and that they have been either restricted to a single Province or focused on cooperatives or subsidies, our aim was to assess what affects whether farmers participate in FSCs and to provide bridging analysis of the degree to which availability and access to subsidies influenced FSC participation, whilst comparing any benefits with non-FSC farmers.

\section{Data and methods}

As stated in the introduction: the purpose of our paper is to assess the role of cooperatives as a complement to work undertaken on direct subsidies (i.e. the complementarity between these two polices). We do so using multi-province data. To achieve this aim, we collected 561 farmer household surveys across 16 provinces, covering 35 FSCs and using a group of non-FSC members as a control group. The survey data focuses on three issues: (1) factors affecting farmer's participation in FSCs; (2) the net income effects of FSCs membership and direct subsidies for farmers; (3) the impact of membership and direct subsidies on investment in agricultural inputs and use of machinery. Since much of the research on FSCs tends to be more localized, our construction of the data covering a range of provinces allows us to extend the prior focus and extent of previous research. ${ }^{8}$

\footnotetext{
6 The subsidies as a proportion of agricultural output was increased in the same period from $0.7 \%$ in 2004 to $3.47 \%$ in 2009.

7 http://nys.mof.gov.cn/zxzyzf/nyzcbhbtzj/201607/t20160719_2363887.html

${ }^{8}$ However, as with any piece of research, ours too has a series of limitations: (1) our sample focuses mainly on cash crop FSCs with omission of others; (2) the sample does not distinguish different varieties of subsidy, but rather relies on the standardized national distribution of those subsidies; (3) though we maintain that the our survey is geographically more extensive than previous research, the use of selected and trained students to deliver the survey does restrict the timing of that research to particular periods in the year.
} 


\section{Data overview}

In order to achieve a geographically balanced sample ${ }^{9}$ to assess the regional differences in farmers' participation in cooperatives, benefits received from membership of FSCs and agricultural subsidies, 16 provinces/autonomous regions/ municipalities were selected.

This included 6 from the eastern area, 5 from the central area, and 5 from the western area. Their macroeconomic figures are listed below (see Table 1). The coverage can be viewed in the Map of China in Figure 1.

Table 1 Selected agricultural related macroeconomic facts in sample provinces (2010)

\begin{tabular}{ccccc}
\hline Region & $\begin{array}{c}\text { GDP per capita } \\
\text { (Ten thousand } \\
\text { Yuan) }\end{array}$ & $\begin{array}{c}\text { Agricultural } \\
\text { output/GDP } \\
(\mathbf{\%})\end{array}$ & $\begin{array}{c}\text { Agricultural } \\
\text { population/ } \\
\text { total population } \\
(\mathbf{\%})\end{array}$ & $\begin{array}{c}\text { Net income per } \\
\text { farmer } \\
\text { household (Yuan) }\end{array}$ \\
\hline Hebei (HB) & 2.83 & 21.13 & 55.50 & 5958 \\
Shandong (SD) & 4.09 & 16.98 & 50.30 & 6990.3 \\
Jiangsu (JS) & 5.26 & 10.37 & 38.24 & 9118.2 \\
Zhejiang (ZJ) & 5.09 & 7.84 & 38.37 & 11302.6 \\
Fujian (FJ) & 3.99 & 15.66 & 42.89 & 7426.9 \\
Hainan (HN) & 2.38 & 39.78 & 50.17 & 5275.4 \\
Eastern average & $\mathbf{3 . 9 4}$ & $\mathbf{1 8 . 6 3}$ & $\mathbf{4 5 . 9 1}$ & $\mathbf{7 6 7 8 . 5 7}$ \\
Inner Mongolia & & 15.80 & 44.50 & 5529.6 \\
(NMG) & 4.72 & 24.83 & 61.50 & 5523.7 \\
Henan (HeN) & 2.46 & 23.91 & 56.99 & 5285.2 \\
Anhui (AH) & 2.07 & 20.11 & 55.94 & 5788.6 \\
Jiangxi (JX) & 2.12 & 23.62 & 56.70 & 5622 \\
Hunan (HuN) & 2.44 & $\mathbf{2 1 . 6 5}$ & $\mathbf{5 5 . 1 3}$ & $\mathbf{5 5 4 9 . 8 2}$ \\
Central average & $\mathbf{2 . 7 6}$ & 16.46 & 54.24 & 4105 \\
Shanxi (S'X) & 2.71 & 25.65 & 63.87 & 3424.7 \\
Gansu (GS) & 1.61 & 23.75 & 59.81 & 5086.9 \\
Sichuan (SC) & 2.14 & 21.68 & 66.20 & 3471.9 \\
Guizhou (GZ) & 1.32 & 25.06 & 65.30 & 3952 \\
Yunnan (YN) & 1.57 & $\mathbf{2 2 . 5 2}$ & $\mathbf{6 1 . 8 8}$ & $\mathbf{4 0 0 8 . 1 0}$ \\
Western average & $\mathbf{1 . 8 7}$ & & & \\
\hline & & & & \\
\hline
\end{tabular}

\footnotetext{
${ }^{9}$ In other word, we selected the sample generally and proportionally based on the numbers of FSCs in different provinces. For example, Eastern China has the highest numbers of FSCs compared to those in Central and Western areas, our sample was thus selected to reflect the shape. However, some provinces have not been included due to data unavailability.
} 


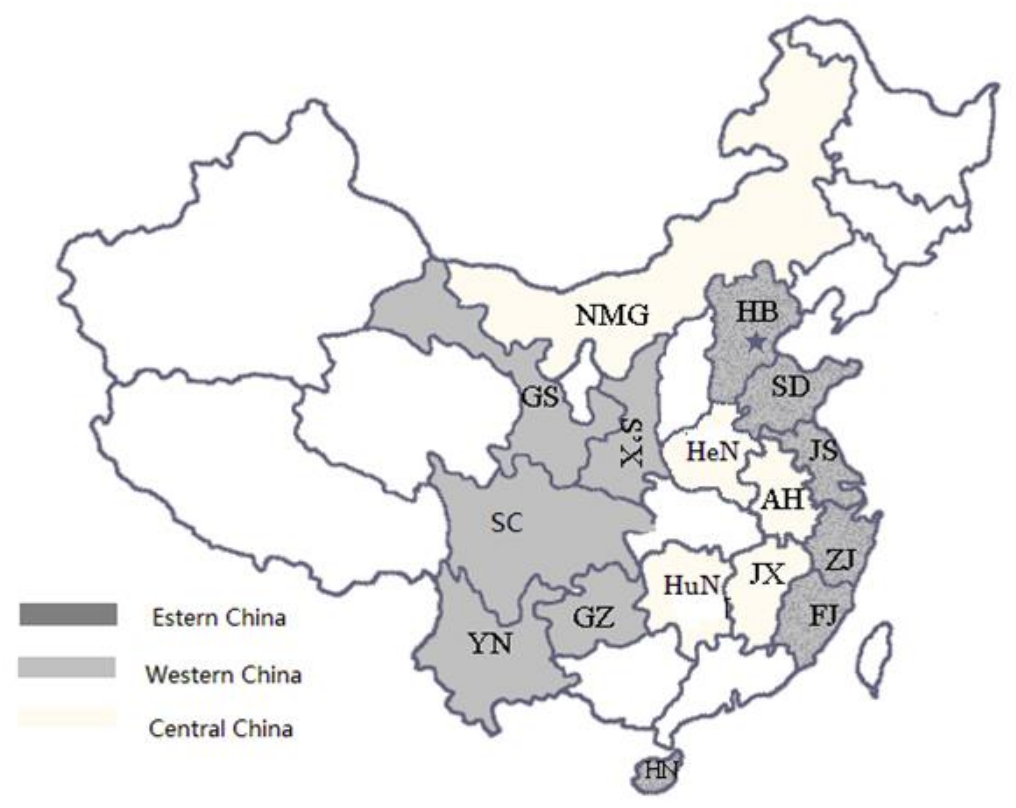

Figure 1: Regional coverage in the surveyed sample

The agricultural population in Table 1 refers to China's register system of identifying citizens (Hukou). It shows that the proportion of the agricultural population as a percentage of the total population, and agricultural outputs as a percentage of GDP are higher in less developed regions than in more developed regions (e.g. western comparing to eastern and central, central comparing to eastern). In addition to these macroeconomic figures, Table 2 further lists some figures relating to farmers' average earnings and average agricultural income across the three regions. As such, Tables 1 and 2 collectively suggest that our sample covers regions with different levels of agricultural development, i.e. in terms of net income per farmer household, average farmer earnings and agricultural income, the eastern area is the most developed region whereas the western is the least developed region. 
Table 2: Differences of average farmer wage and agricultural income from regions in the surveyed sample (Yuan)

\begin{tabular}{|c|c|c|c|c|c|c|c|c|c|c|}
\hline Year & & 12 & & & & & & & & 08 \\
\hline Region & $\begin{array}{l}\text { Wage } \\
\text { income }\end{array}$ & $\begin{array}{l}\text { Agricultural } \\
\text { income }\end{array}$ & $\begin{array}{l}\text { Wage } \\
\text { income }\end{array}$ & $\begin{array}{c}\text { Agricultural } \\
\text { income }\end{array}$ & $\begin{array}{l}\text { Wage } \\
\text { income }\end{array}$ & $\begin{array}{c}\text { Agricultural } \\
\text { income }\end{array}$ & Wage income & $\begin{array}{c}\text { Agricultural } \\
\text { income }\end{array}$ & $\begin{array}{l}\text { Wage } \\
\text { income }\end{array}$ & $\begin{array}{c}\text { Agricultural } \\
\text { income }\end{array}$ \\
\hline Eastern & 4965.5 & 4234.6 & 4287.3 & 3889.2 & 3447.8 & 3471.8 & 2954.6 & 3189.1 & 2659.3 & 3055.9 \\
\hline Central & 3014.5 & 3714.7 & 2558.6 & 3390.3 & 2047.0 & 2984.0 & 1731.5 & 2669.9 & 1575.4 & 2556.1 \\
\hline Western & 2203.6 & 2598.3 & 1892.4 & 2318.4 & 1483.2 & 2043.6 & 1200.8 & 1808.6 & 1070.4 & 1749.8 \\
\hline
\end{tabular}

Questionnaires were used to collect data during the period of Chinese New Year in 2014. Since China Agricultural University has a student population covering the relevant regions and provinces and both students and others typically return home for the Spring Festival (chun jie) winter holiday periods a dependence on targeted students for delivery was both convenient and effective. ${ }^{10}$ The latter involved several considerations: 1) students from China Agricultural University grew up in an agricultural environment and so were familiar with the context and issues being surveyed; 2) as students at a high ranking university they were also familiar with academic and research protocols enabling them to follow a standard research procedure; and 3) perhaps most importantly, each student knew the respondents well and thus had a position of familiarity and trust that could expedite effective clarification of the questionnaire to ensure consistency.

In accordance with the above, a training workshop was provided for the students before their departure. As such, it is reasonable to suggest a priori that every effort was made to ensure the data collection process did not impair data quality. We aimed to achieve a target that in each village visited, data collection should include 15 FSC member households from 1 or 2 FSCs and 5 non FSC member households whose agricultural production was similar to their FSC member counterparts. After excluding invalid questionnaires, respondent coverage consisted of 35 FSCs, and 561 households, disaggregating to 481 FSC members and 80 non-FSC members (see Table 3).

\footnotetext{
${ }^{10}$ Migrant farmers refer to heads of farmer households who work full time in another place and left other family members engaged in agriculture or rent their farmland to others. During this period, most farmer migrants go back rural villages for Chinese New Year from urban cities so that we can capture them in the survey.
} 
Table 3: Descriptive statistics for cooperatives and farmers in the sample

\begin{tabular}{|c|c|c|c|c|c|c|c|c|c|c|}
\hline \multirow{3}{*}{ Region } & \multirow{2}{*}{$\begin{array}{c}\text { Live Stock, Poultry } \\
\text { and Fishery } \\
\text { Cooperatives }\end{array}$} & \multirow[b]{2}{*}{ Crop cooperatives } & \multicolumn{4}{|c|}{ Cooperative members } & \multicolumn{4}{|c|}{ Non cooperative members } \\
\hline & & & $\begin{array}{l}\text { Full time } \\
\text { farmers }\end{array}$ & $\begin{array}{l}\text { Part-time } \\
\text { farmers }\end{array}$ & $\begin{array}{l}\text { Migrant } \\
\text { farmers }\end{array}$ & Total & $\begin{array}{l}\text { Full time } \\
\text { farmers }\end{array}$ & $\begin{array}{c}\text { Part-time } \\
\text { farmers }\end{array}$ & $\begin{array}{l}\text { Migrant } \\
\text { farmers }\end{array}$ & Total \\
\hline & No. $(\%)$ & No. $(\%)$ & No. (\%) & No. $(\%)$ & No. $(\%)$ & No. $(\%)$ & No. $(\%)$ & No. $(\%)$ & No. $(\%)$ & No. (\%) \\
\hline Eastern & $6(35)$ & $6(33)$ & $126(40)$ & $101(80)$ & $12(32)$ & $239(50)$ & $24(67)$ & $18(67)$ & $12(70)$ & $54(67)$ \\
\hline Central & $6(35)$ & $6(33)$ & $100(31)$ & $21(17)$ & $19(51)$ & $140(29)$ & 7 (19) & $7(26)$ & $5(30)$ & $19(24)$ \\
\hline Western & $5(30)$ & $6(34)$ & $92(29)$ & $4(3)$ & $6(17)$ & $102(21)$ & $5(14)$ & $2(7)$ & 0 & $7(9)$ \\
\hline Total & $17(49)$ & $18(51)$ & $318(66)$ & $126(26)$ & $37(8)$ & $481(86)$ & $36(45)$ & $27(34)$ & $17(21)$ & $80(14)$ \\
\hline
\end{tabular}

Table 3 also indicates that the sample achieved a balance in terms of typical FSC types (i.e. Livestock, poultry and fishery, and Crop FSCs) across three regions. We would, therefore, claim that the survey is representative. This includes in terms of farmer classification (full time farmers are the largest group, followed by part time and migrant categories respectively). Clearly, given the actual numbers engaged in farming in China there is always some question mark regarding sampling. As exploratory research based on an identified gap, our work is intended as progress (greater geographical coverage, addressing both aspects of the agricultural problem at issue - membership and subsidies). It should be read in this context.

\section{The model and variables}

We are interested in 3 areas of analysis and these are reflected in the questionnaire:

(1) the factors affecting farmer membership of FSCs;

(2) the impacts of FSC membership and direct subsidies on farmers' net income;

(3) the impacts of FSC membership and direct subsidies on the use of agricultural inputs and machinery.

Our data is initially broken down into 18 variables within 4 categories:

(1) characteristics affecting farmers' participation (level of education, years of farming experience, full time or part time farmers, and being a member of FSC or only having knowledge on FSCs);

(2) characteristics relating to farming business activity (type of FSCs, access to finance, value of agricultural inputs and farm machinery, etc.);

(3) a proxy of the level of local economic development with average house value and geographical locations (Eastern, Central etc.);

(4) farmer households receiving direct agricultural subsidies or not (a proxy of government support). 
The variables are then modelled in order to test how these factors affect the membership of FSCs, net income effects of membership and agricultural direct subsidies, and the impact of membership and direct subsidies on investment in agricultural inputs and use of machinery. Recall that one of the issues we identified in the introduction was that subsidies may only have income effects rather than investment and output effects.

The variables are specified and summarised in Table $4:{ }^{11}$

Table 4 Definitions of variables and descriptive statistics

\begin{tabular}{|c|c|c|c|}
\hline Variables & Description & Mean & Std. Dev \\
\hline \multicolumn{4}{|c|}{ Farmer characteristics related } \\
\hline EDU & Number of years that farmer householder in education & 8.04 & 2.51 \\
\hline EXP & Equal to 1 for farmer householder has at least 6 years in agriculture, 0 otherwise & 0.97 & 0.18 \\
\hline EDU*EXP & Interaction of EDU and EXP & 7.74 & 2.88 \\
\hline FULLTIME & Equal to 1 for full-time farmer, 0 otherwise & 0.63 & 0.48 \\
\hline PARTTIME & Equal to 1 for part-time farmer, 0 otherwise & 0.26 & 0.44 \\
\hline COOP & Equal to 1 for farmer subscribes a FSC, 0 otherwise & 0.86 & 0.35 \\
\hline COOPFAM & Equal to 1 for farmer with reasonable knowledge about farm cooperatives & 0.50 & 0.50 \\
\hline \multicolumn{4}{|c|}{ Farmer business related } \\
\hline LOGNETINCOME & Log of net income (1,000 Yuan) & 2.91 & 1.01 \\
\hline CASHCROP & Equal to 1 for farmer produces cash crop products, 0 otherwise & 0.41 & 0.49 \\
\hline TRADCROP & Equal to 1 for farmer produces traditional cash crop products, 0 otherwise & 0.23 & 0.42 \\
\hline ROC & Equal to 1 for farmer plants more than once per year, 0 otherwise & 0.48 & 0.50 \\
\hline NOLOANACC & Equal to 1 for farmer does not get access to production loans, 0 otherwise & 0.53 & 0.50 \\
\hline AGINPUT & Purchase value of agricultural inputs in 2009 (1,000 Yuan) & 5.73 & 20.58 \\
\hline FARMMACH & Value of farm machinery (1,000 Yuan) & 8.06 & 29.63 \\
\hline AGINPUTS & AGINPUT+ FARMMACH & 13.83 & 35.66 \\
\hline \multicolumn{4}{|c|}{ Local economic development related } \\
\hline HOUSEVALUE & Local average house value (in 1,000 Yuan) & 121.47 & 194.24 \\
\hline EASTERN & Equal to 1 for farmer located in Eastern China, 0 otherwise & 0.52 & 0.50 \\
\hline CENTRAL & Equal to 1 for farmer located in Central China, 0 otherwise & 0.28 & 0.45 \\
\hline \multicolumn{4}{|c|}{ Government supporting related } \\
\hline AGSUB & Equal to 1 for farmer received agricultural subsidies, 0 otherwise & 0.80 & 0.40 \\
\hline
\end{tabular}

The structure of our model is designed to avoid potential problems. For example, some have argued that the net income differences between members and non-members of FSCs may not be fully attributable to participation in cooperatives (see Karantininis and Zago 2001; Greene 2008), e.g. individual capability. This suggests that there might be an issue with the endogenous variables.

\footnotetext{
11 Non-FSC member, migrant, and Western are allowed for based on standard statistical procedures (see
} Freedman 2010) 
To address this problem, we use a two-stage treatment effect, since this excludes endogenous heterogeneity. In this treatment effect model, the effect of participation in cooperatives on farmers' income is modelled in two stages:

$$
\begin{aligned}
& y_{i}=\beta x_{i}+\delta z_{i}+\varepsilon_{i} \\
& z_{i}^{*}=w_{i} \gamma+u_{i}
\end{aligned}
$$

Where $y_{i}$ is the net income of farmer $i, x_{i}$ is a vector of variables for farmer $i$ that affects that farmer's net income, $z_{i}$ is an indicator variable equal to one if the farmer participates in a cooperative, $w_{i}$ is a vector variable for farmer $i$ that affects that farmer's decision whether to join the cooperative or not, and $\varepsilon_{i}$ and $u_{i}$ are disturbance terms assumed to be distributed i.i.d. bivariate normal with zero means. More specifically, the regression equation is as follows:

$$
\log \left(\text { Net } \quad \text { income }_{i}\right)=\beta x_{i}+\delta z_{i}+\lambda s_{i}+\gamma h_{i}+\varepsilon_{i}
$$

Where $x_{i}$ is a vector of exogenous variables that affect farmer households' net income, which are the same as in the first step $Z_{i}$ is the prediction of participation in cooperatives, $s_{i}$ is the subsidy of farmer $i, h$ is the hazard term. ${ }^{12}$

Following the usual two-stage treatment effect model, we model the farmer-cooperative participation decision variable $z_{i}$ as:

$$
z_{i}= \begin{cases}1, & \text { if } z_{i}^{*}>0 \\ 0, & \text { otherwise }\end{cases}
$$

Where $z_{i}^{*}$ is a latent variable in a random utility framework equal to the difference in farmer indirect utility from a farmer participating in and not participating in a farmer cooperative:

$$
z_{i}^{*}=V\left(z_{i}=1 \mid x_{i}, w_{i}\right)-V\left(z_{i}=0 \mid x_{i}, w_{i}\right)
$$

We then use the standard Heckit estimator to derive estimates for the parameters.

\section{Results and discussion}

We set out the results following the three areas for analysis previously stated: (1) the factors affecting farmer membership of FSCs; (2) the impacts of FSC membership and direct subsidies

12 The use of an exclusion variable to manage endogeneity in econometric analysis inevitably creates dispute regarding what to select and whether one might opt for Heckman correction. See Freedman (2010). 
on farmers' net income; (3) the impacts of FSC membership and direct subsidies on the use of agricultural inputs and machinery.

Table 5 summarizes our initial model parameter estimates. It divides into Model 1 and Model 2 based on the two stage treatment.

Table 5 Model parameter estimates: membership, subsidies and farmer net income

\begin{tabular}{|c|c|c|c|c|c|c|c|c|}
\hline \multirow[t]{3}{*}{ Variables } & \multicolumn{4}{|c|}{1} & \multicolumn{4}{|c|}{2} \\
\hline & \multicolumn{2}{|c|}{ LOGNETINCOME } & \multicolumn{2}{|c|}{$\mathrm{COOP}=1$} & \multicolumn{2}{|c|}{ LOGNETINCOME } & \multicolumn{2}{|c|}{$\mathrm{COOP}=1$} \\
\hline & Estimates & SE & Estimates & SE & Estimates & SE & Estimates & SE \\
\hline EDU & $0.105^{*}$ & {$[0.056]$} & 0.022 & {$[0.034]$} & $0.108^{*}$ & {$[0.105]$} & 0.02 & [0.033] \\
\hline EXP & $1.354 * *$ & {$[0.607]$} & $0.536^{*}$ & {$[0.317]$} & $1.370^{* *}$ & {$[0.603]$} & $0.550^{*}$ & [0.313] \\
\hline EDU*EXP & $-0.107^{*}$ & {$[0.057]$} & & & $-0.110^{*}$ & {$[0.057]$} & & \\
\hline FULLTIME & $-0.450 * *$ & {$[0190]$} & $1.433 * * *$ & {$[0.210]$} & $-0.464 * *$ & {$[0.184]$} & $1.422 * * *$ & {$[0.207]$} \\
\hline PARTTIME & $-0.306^{*}$ & {$[0.178]$} & $1.338 * * *$ & {$[0.232]$} & $-0.322 *$ & {$[0.173]$} & $1.347 * * *$ & {$[0.233]$} \\
\hline COOP & $0.800 * * *$ & {$[0.298]$} & & & $0.848 * * *$ & {$[0.272]$} & & \\
\hline COOPFAM & & & $0.703 * * *$ & {$[0.221]$} & & & $0.671 * * *$ & {$[0.211]$} \\
\hline CASHCROP & 0.024 & [0.086] & $0.438 * *$ & [0.204] & 0.023 & [0.092] & $0.422 * *$ & [0.190] \\
\hline TRADCROP & $-0.201^{*}$ & [0.113] & 0.096 & [0.203] & $-0.204^{*}$ & [0.113] & 0.149 & [0.196] \\
\hline ROC & $0.250 * * *$ & {$[0.079]$} & & & $0.245^{* * *}$ & {$[0.078]$} & & \\
\hline NOLOANACC & $-0.143^{*}$ & {$[0.086]$} & $0.423 * * *$ & {$[0.149]$} & $-0.147 *$ & {$[0.086]$} & $0.434 * * *$ & {$[0.142]$} \\
\hline AGINPUT & $0.005 * * *$ & {$[0.001]$} & $-0.005^{* * *}$ & {$[0.002]$} & & & & \\
\hline FARMMACH & $0.004 * *$ & [0.002] & 0.008 & [0.009] & & & & \\
\hline AGINPUTS & & & & & $0.005^{* * *}$ & {$[0.001]$} & $-0.004^{*}$ & {$[0.002]$} \\
\hline HOUSEVALUE & $0.002 * *$ & {$[0.001]$} & $0.004 * * *$ & {$[0.001]$} & $0.002 * * *$ & {$[0.001]$} & $0.004^{* * *}$ & {$[0.001]$} \\
\hline EAST & $0.331 * * *$ & {$[0.091]$} & $-0.910 * * *$ & {$[0.255]$} & $0.335^{* * *}$ & {$[0.091]$} & $-0.882 * * *$ & {$[0.254]$} \\
\hline CENTRAL & $0.252 * *$ & {$[0.121]$} & 0.0442 & {$[0.275]$} & $0.254 * *$ & {$[0.117]$} & -0.02 & {$[0.267]$} \\
\hline AGSUB & $0.343 * * *$ & {$[0.108]$} & $0.427 * *$ & {$[0.178]$} & $0.341 * * *$ & {$[0.108]$} & $0.407 * *$ & {$[0.175]$} \\
\hline INTERCEPT & 0.44 & {$[0.668]$} & $-1.768 * * *$ & {$[0.535]$} & 0.397 & {$[0.665]$} & $-1.723 * * *$ & {$[0.524]$} \\
\hline ATHRHO & $-0.739 * * *$ & {$[0.272]$} & & & $-0.779 * * *$ & {$[0.253]$} & & \\
\hline LNSIGMA & $-0.135 * *$ & {$[0.062]$} & & & $-0.129 * *$ & {$[0.060]$} & & \\
\hline OBSERVATIONS & & & & & & & & \\
\hline
\end{tabular}

\section{(1) Factors affecting farmer membership of FSCs}

The factors affecting farmers' membership (Deng et al. 2010; Zheng et al. 2011, 2012; Yang and Liu 2012; Ito et al. 2012) can be classified into two categories: (1) the characteristics of 
farmers such as education level, psychological barriers, time committed to agricultural production (i.e. full time or part time farmer), length of engagement (i.e. experience); (2) central and local governments' policies such as promoting FSCs and agricultural subsidies.

In our study, we first examine what factors contribute to farmer membership of FSCs. This was carried out in the first stage of the regression in Table 5, and the results can be referred to in the column ' $\mathrm{COOP}=1$ ' for Model 1 . With regards to the variables relating to farmer characteristics, both full time farmer (FULLTIME) and part time farmer (PARTTIME) categories exhibit positive and significant associations with FSC participation. The findings also suggest, years of farming experience (EXP) and greater knowledge (COOPFAM) of the way in which FSCs function influence membership with $1 \%$ of statistical significance. As such, our results generally support the findings in the studies referred to in the introduction (and below).

Moving on to characteristics of farming business activities, our findings suggest that farmers involved in cash crop activity (CASHCROP) are more likely to participate in FSCs compared to farmers breeding livestock, poultry and or fish. This seems reasonable in the sense that one can readily perceive the benefits of technical support for cash crops. The results also indicate that farmers who invest more in agricultural input are less willing to take part in FSCs as AGINPUT has negative and significant effect. This might be due to the fact that farmers with high agricultural input use are most likely large scale farmers who have better bargaining power when dealing with buyers in the market, and as such their motivation to participate in cooperatives may be lower than small scale farmers, based on this variable. The finding also suggests that participants' independent access to finance (NOLOANACC) seems to adversely affect cooperative membership. Those with lower levels of access to finance seem to view FSC membership as a source of support. In one sense, FSCs seem to be operating effectively, since they are acting as a substitute for formal financing. Moreover, the values of agricultural machinery exhibit little effect on membership.

We further assess if there are differences between regions with different economic development levels in terms of farmers' attitudes towards FSC participation. This is because research on regional differences in relation to FSCs participation behaviour and benefits has largely been neglected in the literature (Cho et al. 2010). The agricultural development does not only affect farmers' characteristics and farmer' organizations in the region but also leads to different agricultural priorities and supporting measurements (e.g. subsidy policies).

As previously noted there are few regional studies. Yang and Liu (2012) conducted an investigation to investigate whether FSCs and agricultural specialisation had improved rural 
income from 2459 villages in 6 provinces in China and concluded that it indicated "great significance to rural income growth". Nevertheless, their data was collected in 2003 when the FSC Law had not been in effect. Other studies are found mainly based on cases in one province. Examples of these studies such as Zheng et al. (2011, 2012) conducted in Jilin province, Ding et al. (2011) in Yunnan province, Cai (2011) in Shandong province and Ito et al. (2012) in Jiangshu province.

Our results in Table 5 show, compared to farmers from western China, farmers living in the eastern region (EASTERN) are less likely to join FSCs. The main reason for this seems to be that farmers in eastern China have more opportunity to find employment in non-agricultural sectors. This region has higher industrialization and a lower proportion of agricultural output to GDP (see Table 1, a typical case is Zhejiang province).

In our study, agricultural subsidies (AGSUB) are a proxy for government support policy (Deng et al. 2010). We found farmers receiving subsidies have positive attitudes to participation in FSCs, which suggests that the government's subsidy policy has played a role in encouraging farmers' engagement with agriculture. It seems very likely that this consequence will be more effective in the future as the new subsidy of 'Agriculture Support and Protection Subsidy' (including grain subsidy, seed subsidy, and aggregated inputs subsidy) is aimed at supporting moderate and large-scale management operators (e.g. cooperatives, large scale farmers, family farms and agricultural social service organizations) to encourage large scale farming to use farmland effectively and efficiently. Considering the effect relates the promotion of subsidies to FSC membership, we would argue that this is evidence that cooperatives and subsidies involve complementarities.

To summarize, statistical analysis of the survey provides new insight into the areas which are not very well evidenced in the previous literature. Notably, findings for participation relating to regional differences and agricultural subsidies. The analysis also adds further evidence regarding general factors influencing farmers' participation in and behaviour towards FSCs, and the complementary effect between FSC membership and government's direct subsidies.

\section{(2) The impacts of FSC membership and direct subsidies on farmers' net income}

In the literature, FSCs are found to be effective in raising the level of specialisation (Yang and Liu 2012), expanding farmers' business scope (Zheng et al. 2011) and FSC membership is correlated with rural income (Deng et al. 2010; Yang and Liu 2012). However, evidence suggests that the level of farmers' participation in FSCs is low, ranging from 10\% (Zheng et al. 2012), to $15.5 \%$ (Ito et al. 2012). Given this low level of participation, Zheng et al. (2012) argued that farmers' full benefits from joining FSCs might be hard to accurately assess. 
As discussed in the last section, the main intention of farmers' participation is to improve their financial position. As such, in the second stage in Table 5 (see the column of 'LOGNETINCOME' for Model 1), whether the participation and subsidies can benefit farmers and what factors contribute to farmers' net income are analysed. The benefit here is measured by farmers' net income at the end of 2010 in terms of RMB (1000 Yuan). We firstly find that education background (EDU) and agricultural experience (EXP) are important factors for income generation. This, of course, is what one would expect, given that both create human capital, which may augment productivity. Secondly compared to migrant farmers, full-time and part-time farmers earn less as both FULLTIME and PARTIME are negative with moderate to weak statistical significance respectively, of which full time farmers earn less than migrant counterparts. Again, this accords with what one might intuit, it is basic to the reasons why ruralurban migrants are migrants, in turn affecting the profile of those who remain.

Thirdly, cooperative membership (COOP) and subsidy receiving (AGSUB) have positive and significant effects on farmer income generation. These findings are consistent with other studies. For example, Ito et al. (2012) suggested that cooperatives were important for farmers, especially for small scale farmers, to improve their economic status. In a study carried out in Shangdong province, Cai (2011) also found that the average net income of apple cooperative members was higher than that of non-cooperative members. With regards to research on the relationship between agricultural subsidies and farmer net income, Huang et al. (2011, 2013) and Yi (2015) indicated that subsidies were positive and significant in farmers' net income. Our findings firmly support both Huang et al and Yi.

In addition, we infer that promoting cooperative membership and allocating agricultural subsidies are both important agricultural policies. In combination they are able to provide support to farmers in China. This, however, is highly conditional on the actual mechanisms used to promote membership, how this becomes participation and whether in fact the recipient of subsidies is the current farmer. These, of course, are important institutional issues regarding the nuance of rule systems and policy design (see next subsection for more evidence and conclusion for additional comment).

Fourthly, the results also identified that multiple plantings in a year (ROC) would increase net income significantly and no loan access (NOLOANACC) would decrease net income. The results are reasonable and expected. Fifthly, the coefficients of AGINPUT (farmers' agricultural input investment) and FARMMACH (farmers' agricultural machinery investment) are both positive and statistically significant which indicate that improving technology by investing in equipment is an effective method to increase farmers' income. 
Moving to regional differences in farmers' net income, the findings suggest that farmers living in the eastern region (EASTERN) can earn far more than farmers from western China; and farmers from central China (CENTRAL) have higher net income than their peers in western regions. The results are consistent with discussions earlier about regional economic imbalance. A positive and statistical significance with the coefficient of HOUSEVALUE further suggests that commercialization and urbanization play an important role in increasing farmers' net income in China.

(3) The impacts of FSC membership and direct subsidies on the use of agricultural inputs and machinery

Both direct subsidies and FSCs membership have net income effects. However, a further issue is whether direct subsidies and FSCs membership also make greater use of agricultural inputs and investments in machinery. Intuitively one would expect the answer to be 'yes'. However, previous research has found the opposite to be true, albeit based on highly restricted datasets etc.

For instance, Kirwan (2008) found that farmland owners captured 75 percent of the grain subsidy but only 25 percent of them are actually in farming. As argued by Huang Jikun, the 'grain subsidy' and 'comprehensive input subsidy' play zero role in encouraging agricultural production rather they act as an income subsidy ${ }^{13}$. This debate calls for more evidence. Similarly, one might expect that membership of FSCs would lead to greater investment in agricultural input and use of machinery, which may involve payment without individual ownership or an increase in ownership (a different kind of investment). ${ }^{14}$

In order to explore relations above we rerun our two-stage treatment model. The results are reported in Table 6:

${ }^{13}$ http://china.caixin.com/2014-12-30/100769339.html. (accessed 30 July 2015)

14 Note, one can distinguish the majority of small-scale FSCs operating within a single village or restricted locality from large scale and more commercial FSCs of 3 kinds based on consolidation and perhaps vertical integration within stages of a supply chain: 1) Production oriented FSCs with a trademarked output and stable sales channels; 2) Sales and distribution FSCs; 3) Production-processing-marketing FSCs. Those 3 kinds are more capital intensive than smaller local FSCs and are liable to have more significant associations between FSC status and investment levels (See Wu 2011). However, these are not the focus of our research. 
Table 6 Model parameter estimates: membership, subsidies and farmer agro investment

\begin{tabular}{|c|c|c|c|c|c|c|c|c|c|c|c|c|}
\hline \multirow{3}{*}{ Variables } & \multicolumn{4}{|c|}{ Model 1} & \multicolumn{4}{|c|}{ Model 2} & \multicolumn{4}{|c|}{ Model 3} \\
\hline & \multicolumn{2}{|c|}{ AGINPUT } & \multicolumn{2}{|c|}{$\mathrm{COOP}=1$} & \multicolumn{2}{|c|}{ FARMACH } & \multicolumn{2}{|c|}{$\mathrm{COOP}=1$} & \multicolumn{2}{|c|}{ AGINPUTS } & \multicolumn{2}{|c|}{$\mathrm{COOP}=1$} \\
\hline & ESTIMATES & SE & ESTIMATES & SE & ESTIMATES & SE & ESTIMATES & SE & ESTIMATES & SE & ESTIMATES & SE \\
\hline$\overline{\text { EDU }}$ & -0.447 & [1.188] & -0.009 & {$[0.035]$} & $0.814^{*}$ & {$[0.488]$} & -0.0141 & [0.0358] & 0.363 & [1.306] & -0.00974 & {$[0.0353]$} \\
\hline EXP & -10.55 & [13.38] & $0.562 *$ & [0.333] & $11.58 *$ & [5.925] & $0.551 *$ & [0.334] & 0.9 & {$[14.60]$} & $0.558^{*}$ & {$[0.333]$} \\
\hline $\mathbf{E D U}^{*} \mathbf{E X P}$ & 1.24 & {$[1.60]$} & & & $-1.001 *$ & [0.593] & & & 0.243 & {$[1.725]$} & & \\
\hline FULLTIME & 7.674 & [4.971] & $1.339 * * *$ & {$[0.212]$} & -0.361 & {$[1.740]$} & $1.287 * * *$ & {$[0.218]$} & 7.183 & {$[5.225]$} & $1.347 * * *$ & {$[0.213]$} \\
\hline PARTTIME & 3.773 & [3.933] & $1.344^{* * * *}$ & -0.233 & -0.713 & [2.647] & $1.323 * * *$ & {$[0.235]$} & 2.92 & [4.683] & $1.348 * * *$ & {$[0.234]$} \\
\hline COOP & -3.881 & [4.848] & & & $7.324 * *$ & [3.372] & & & 3.881 & {$[6.068]$} & & \\
\hline COOPFAM & & & $0.888^{* * *}$ & {$[0.165]$} & & & $0.855^{* * *}$ & {$[0.171]$} & & & 3.881 & {$[6.068]$} \\
\hline ROC & $9.398 * *$ & {$[3.775]$} & & & -2.664 & {$[2.174]$} & & & 6.764 & [4.327] & & \\
\hline NOLOANACC & 0.714 & [2.077] & $0.388 * *$ & {$[0.158]$} & -1.322 & {$[2.566]$} & $0.400 * *$ & {$[0.156]$} & -0.657 & {$[3.297]$} & $0.393 * *$ & {$[0.158]$} \\
\hline CASHCROP & -3.539 & [3.866] & $0.537 * * *$ & {$[0.192]$} & -1.091 & {$[2.567]$} & $0.554 * * *$ & {$[0.191]$} & -4.674 & {$[4.622]$} & $0.540 * * *$ & {$[0.192]$} \\
\hline TRADCROP & $-10.26^{* * *}$ & [3.771] & 0.0436 & [0.199] & $3.113^{*}$ & [1.809] & 0.054 & [0.198] & $-7.144^{*}$ & [4.166] & 0.045 & [0.199] \\
\hline EAST & $5.690 * * *$ & [1.390] & $-0.999 * * *$ & {$[0.25]$} & 2.495 & [1.649] & $-1.002 * * *$ & {$[0.25]$} & 8.232 *** & [2.084] & $-0.999 * * *$ & {$[0.251]$} \\
\hline CENTRAL & $17.99 * * *$ & [5.334] & -0.074 & {$[0.283]$} & -0.913 & [1.731] & -0.129 & {$[0.282]$} & $17.06 * * * *$ & [5.583] & -0.073 & {$[0.283]$} \\
\hline $\begin{array}{l}\text { HOUSEVALU } \\
\text { E }\end{array}$ & 0.0138 & {$[0.011]$} & $0.003^{* * *}$ & {$[0.001]$} & 0.003 & [0.004] & $0.002 * * *$ & [0.001] & 0.016 & $\begin{array}{c}{[0.0137} \\
]\end{array}$ & $0.003^{* * *}$ & {$[0.001]$} \\
\hline AGSUB & 2.247 & [1.714] & $0.455^{* * *}$ & [0.171] & -0.987 & [1.577] & $0.444 * * *$ & {$[0.17]$} & 1.219 & [2.259] & $0.455^{* * *}$ & {$[0.171]$} \\
\hline INTERCEPT & -2.849 & [9.902] & $-1.280 * *$ & {$[0.582]$} & -8.925 & {$[5.826]$} & $-1.146^{*}$ & {$[0.591]$} & -11.87 & {$[11.51]$} & $-1.291 * *$ & {$[0.584]$} \\
\hline ATHRHO & $-0.124^{*}$ & {$[0.066]$} & & & -0.0812 & {$[0.0591]$} & & & $-0.157 * *$ & {$[0.069]$} & & \\
\hline INSIMA & $3.344 * * *$ & {$[0.252]$} & & & $3.022 * * *$ & [0.247] & & & $3.554 * * *$ & {$[0.188]$} & & \\
\hline $\begin{array}{l}\text { OBSERVATIO } \\
\text { NS }\end{array}$ & 561 & & 561 & & 561 & & 561 & & 561 & & 561 & \\
\hline
\end{tabular}

Standard errors in parentheses, $* * * \mathrm{p}<0.01, * * \mathrm{p}<0.05, * \mathrm{p}<0.1$.

Coefficient of ATHRHO and LNSIGMA are significant, indicating necessarily to control the endogeneity bias in the model.

Models 1 and 2 separately examine cooperative farmers' purchasing values in agricultural input (AGINPUT) and agricultural machinery (FARMACH)

respectively, and Model 3 is the combination of the both as the total value of agro investment (AGINPUTS) 
Three findings are revealed in Table 6:

(1) FSC membership (COOP) does not seem to lead to any greater use of inputs (AGINPUT) than receipt of subsidies. However, membership does promote use of machinery (FARMACH). This finding is consistent with the discussion in the literature and proves that modern FSCs have become an important vehicle for facilitating new agricultural technologies (Yang and Liu 2012; Liang and Hendrikse 2013; Yan and Chen 2013). However:

(2) The agricultural subsidies received by farmers from FSCs do not help increase investments either in agricultural input or machineries as AGSUB neither has statistical significance on AGINPUT, FARMACH nor on AGINPUTS.

The results in our sample here provide strong evidence to support Huang et al's (2011) claim that the original purpose of subsidy policy is distorted as agricultural subsidies (in particular 'grain subsidy') ${ }^{15}$, to some extent become a kind of 'income subsidy'. Concomitantly, input subsidies have been distributed without direct reference to the extent of actual inputs used.

In both cases, the greater part of the subsidy has income effects without necessarily directly improving agricultural production (see Huang et al. 2011; Yi et al. 2015). ${ }^{16}$ This is reflected in our Model 3 regression result. Again, this indicates that some of the potential of the combination of FSC membership and subsidies is being dissipated and this is likely an institutional issue of design.

(3) In contrast to farmers living in western region (WESTERN), farmers from the eastern (EASTERN) and central (CENTRAL) regions significantly invest more in agricultural input (AGINPUT) but not in agricultural machineries (FARMACH). The reasonable explanation for this finding is that unlike investing in agricultural inputs which closely links to the farmers' financial position, investing in agricultural machinery is more restricted to geographical production conditions. That is, whether the land and land use are suitable for using machinery or suitable for a particular type of machinery (see Wan and Cheng 2001).

\section{Conclusion}

As argued in the introduction, research on both cooperatives and subsidies has been limited in various ways. Our study goes some way to addressing this. We have considered both membership and participation in FSCs and subsidy effects and have done so based on a

\footnotetext{
${ }^{15}$ As previously noted, the majority farming household subsidy has been for grain, and this has typically been distributed to the registered land contractee (who may or may not be the land user).

${ }^{16}$ See also http://china.caixin.com/2014-12-30/100769339.html, accessed 30 July 2015.
} 
geographically extensive survey that is in various ways representative. Specifically, we have modelled the data collected from 35 FSCs and 561 farmer householders in 16 provinces, by exploring factors affecting membership of FSCs, net income and agricultural investment effects in relation to membership and direct subsidies.

The findings and the contributions of this paper are threefold. First, with regards to the factors affecting membership of FSCs, we found FSCs to be most attractive based on regional dynamics (due to contrasting alternative employment potential etc) and where farming is small scale and farmers are full-time. In addition, we found farmers receiving subsidies have positive attitudes to participation in FSCs, which suggests there are likely complementarity effects between cooperative membership and subsidy provision. However, this is limited based on other conditioning or contingent factors that affect the design and implementation of policy. Clearly, policy is liable to be more effective if it can be targeted at actual farmers rather than previous or absent owners and can be focused in ways that maximise potential impact. That is, if policy targets subsidies by sector, region and scale of farming. This in fact has begun to occur in some ways via the new 'Agricultural Support and Protection Subsidy' in 2016 (including grain subsidy, quality seed subsidy, and comprehensive input subsidy). This is aimed at supporting moderate scale management operators (e.g. cooperatives, large scale farmers, family farms and agricultural social service organizations). How this will play out is yet to be seen.

Second, in relation to net income effects of FSC membership and subsidies, our results suggest that FSC members earned more than non-members. What is more, subsidies received by farmers are important ways of generating income. This is important. It suggests that at minimum FSC membership and subsidies together may be a way of balancing out, over time, some of the pull factors that are creating the "crisis" in agriculture in China. That is, the ruralurban divide. This, of course is only one strand of policy for an extremely complex issue but it nonetheless should not be neglected. Raising the standards of knowledge skills and commitment on a local basis is necessarily a long-term issue of developing effective networks that in turn show benefits for participants, creating a virtuous circle of growth that potentially affects both food security and rural sustainability. This, of course, is precisely what the state is intent upon.

However, this leads to our third finding. In terms of the agricultural investment effect of FSC membership and subsidies, analysis of our survey evidence suggests that despite FSC membership contributing to the use of machinery, there is little impact on promoting farmer agricultural investment (neither in input nor in machinery). Clearly, more thought needs to be given to this issue. It too involves multiple factors and considerations (suggesting both 
institutional reassessment and scope for follow up research, perhaps cross referenced based on different methods, see Morgan and Patomäki 2017). Machinery may only be appropriate if land and land use allow and if scale makes it cost effective given the relative timing of use of machines. Cooperatives provide one way to collectivise costs and risk if they are appropriately incentivised and managed, but this requires training, knowledge and skills and then effective logistics (if, for example, machinery is required by all participants at approximately the same time due to harvest pressures etc). These are barriers that require the development of trust and this requires national policy to be locally committed to (for issues of trust see Colledge et al. 2014). Clearly, time will tell how effective the state is in developing along these lines.

\section{References}

Cai, F., and Y. Du. 2006. "The Changing Nature of Rural Poverty and New Policy Orientations". Chinese Economy 39(4):10-24.

Carter, C., F. Zhong, and J. Zhu. 2012. "Advances in Chinese Agriculture and Its Global Implications". Applied Economic Perspectives and Policy 34 (1):1-36.

Chai, R. 2011. "Transaction Cost and Income Saving through Cooperatives: Evidence from Orchard Cooperatives of Shandong Province in China. China Rural Economy (in Chinese) 1: 58-65.

Chan, K.W., and M. Ip. 2014a. "The 'Legal Environment' of Cooperatives in the People's Republic of China - A Narrative". Chinese Economy 47 (4): 8-31.

Chan, K.W., and M. Ip. 2014b. "Cooperatives in China - A Promising Player in Chinese Economy". Chinese Economy 47(4): 3-7.

Cheng, G. Q., and M.D. Zhu. 2012. "China's Agricultural Subsidy System and Policy Choice in Mid-term Stage of Industrialization". Management World (in Chinese) 1:9-20.

Cho, S. H., Z. Chen, and N. C. Poudyal. 2010. "Spatial Structure of Agricultural Production in China". Applied Economics 42 (16):2031-2040.

Colledge, B., J. Morgan, and R. Tench. 2014. "The Concept(s) of Trust in Late Modernity, the Relevance of Realist Social Theory". Journal for the Theory of Social Behaviour 44 (4): 481-503.

Deng, H., J. Huang, Z. Xu, and S. Rozelle. 2010. "Policy Support and Emerging Farmer Professional Cooperatives in Rural China". China Economic Review 21(4): 495-507.

Freedman, D. 2010. Statistical Models and Causal Inference. Cambridge: Cambridge University Press.

Gale, F. 2009. "Financial Reforms Push Capital to the Countryside". Chinese Economy, 42(5): 58-78.

Greene, W. H. 2008. Econometric Analysis. Upper Saddle River, NJ: Prentice-Hall.

Gui, Y., J. W. Berry, and Y. Zheng. 2012. "Migrant Worker Acculturation in China". International Journal of Intercultural Relations 36 (4): 598- 610.

He, W. L., R. X. Zhu, Y. X. Huang, X. F. Zhao, and H. Ma. 2010. "Analysis of the Implement Effect of China's Policy of Subsidizing the Purchase of Agricultural Machinery". Journal of Agricultural Mechanization Research (in Chinese) 4:195-198.

Huang, J., X. Wang, H. Zhi, Z. Huang, and S. Rozelle. 2011. "Subsidies and Distortions in China's Agriculture: Evidence from Producer-level Data". Australian Journal of Agricultural and Resource Economics 55 (1): 53-71.

Huang, J., X. Wang, and S. Rozelle. 2013. "The Subsidization of Farming Households in China's Agriculture". Food Policy 41 (44):124-132. 
Ito, J., Z. Bao, and Q. Su. 2012. "Distributional Effects of Agricultural Cooperatives in China: Exclusion of Smallholders and Potential Gains on Participation". Food Policy 37 (6):700-709.

Ji, J., X. Yu, and F. Zhong. 2012. "Machinery Investment Decision and Off-farm Employment in Rural China". China Economic Review 23 (1):71-80.

Karantininis, K., and A. Zago. 2001. "Endogenous Membership in Mixed Duopsonies". American Journal of Agricultural Economics 83 (5):1266-1272.

Kirwan, B. E. 2008. "The Incidence of U.S. Agricultural Subsidies on Farmland Rental Rates". Journal of Political Economy 117 (1): 138-164.

Liang, Q., and G. Hendrikse. 2013. "Core and Common Members in the Genesis of Farmer Cooperatives in China". Managerial and Decision Economics 34 (3-5):244-257.

Lin, J. Y. 1990. "Collectivization and China's Agricultural Crisis in 1959-1961”. Journal of Political Economy 98 (6):1228-1252.

Lin, J. Y. 1993. "Exit Rights, Exit Costs, and Shirking in Agricultural Cooperatives: A Reply". Journal of Comparative Economics 17 (2):504-520.

Lin, J. Y. 1997. "Institutional Reforms and Dynamics of Agricultural Growth in China". Food Policy 22 (3): 201-212.

Meng, L. 2012. "Can Grain Subsidies Impede Rural-urban Migration in Hinterland China? Evidence from Field Surveys". China Economic Review 23 (3): 729-741.

Morgan, J., and H. Patomäki. 2017. "Contrast Explanation in Economics: Its Context, Meaning, and Potential". Cambridge Journal of Economics 41 (5):1391-1418.

NBSC. 2005. China Compendium of Statistics 1949-2004. Department of Comprehensive Statistics, National Bureau of Statistics, China Statistics Press.

NSBC. 2004-2009. China National Statistical Yearbook. Beijing: China Statistical Press.

NBSC. 2009. Statistical Communiqué on Labour and Social Security Development in 2008. National Bureau of Statistics of China.

NSBC. 2015. China's National Statistical Yearbook. Beijing: China Statistical Press

OECD (The Organisation for Economic Co-operation and Development). 2009. Agricultural Policies in Emerging Economies 2009: Monitoring and Evaluation. Paris.

Taubmann, W., T. Herberer, and F. Jie. 2003. "Economic Structures and Changes in Rural Enterprises in China at the End of the Twentieth Century: The Privatization of Enterprises". Chinese Economy 36 (6): 5-88.

Tian, W., and Z. Zhou. 2011. "Fluctuations of Prices in the World Grain Market: Policy Responses by the Chinese Government". Journal of Chemical Information \& Modelling 52 (2):19-28.

Wan, G. H., and E. Cheng. 2001. "Effects of Land Fragmentation and Returns to Scale in the Chinese Farming Sector". Applied Economics 33 (2):183 -194.

Wang D., and F. Cai. 2004. "Readjustment of Macroeconomic Policy and Growth of Farmers' Income". Chinese Economy 37(2): 29-46.

$\mathrm{Wu}$, L. 2011. "Study on Performance of Grain Subsidy Policies from the Perspective of Farmers' Producing Behaviour". PhD thesis (in Chinese). Zhejiang University.

Yan, H., and Y. Chen. 2013. "Debating the Rural Cooperative Movement in China, the Past and the Present". Journal of Peasant Studies 40 (6): 955-981.

Xu, X., K. Shao, Q. Liang, H. Guo, J. Lu., and Z. Huang. 2013. "Entry of Chinese Small Farmers into Big Markets". Chinese Economy 46(1): 7-19.

Yang, D., and Z. Liu. 2012. "Does Farmer Economic Organization and Agricultural Specialization Improve Rural Income? Evidence from China". Economic Modelling 9 (3): 990-993. 
Yi, F., D. Sun, and Y. Zhou. 2015. "Grain Subsidy, Liquidity Constraints and Food SecurityImpact of the Grain Subsidy Program on the Grain-sown Areas in China". Food Policy 50 (50): 114-124.

Zhao, Li, and P. Yuan. 2014. "Rural Cooperative in China". Chinese Economy 47(4): 32-62.

Zhao, Y. 2006. "The Main Problems and Countermeasures of China's Rural Financial System". Chinese Economy 39(2): 57-70.

Zheng, S., Z. Wang, and S. Song. 2011. "Farmers' Behaviours and Performance in Cooperatives in Jilin Province of China: A Case Study". The Social Science Journal 48 (3): 449-457.

Zheng, S., Z. Wang, and T.O. Awokuse. 2012. "Determinants of Producers' Participation in Agricultural Cooperatives: Evidence from Northern China". Applied Economic Perspectives and Policy 34 (1):167-186.

Zheng, S., D. Lambert, S. Wang, and Z. Wang. 2013. "Effects of Agricultural Subsidy Policies on Comparative Advantage and Production Protection in China". Chinese Economy 46(1): 20-37. 